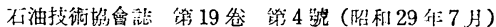

JOURNAL OF THE JAPANESE ASSOCIATION OF PETROLEUM TECHNOLOGISTS

VOL. 19, NO. 4 (July, 1954)

\title{
Fundamental Properties of Cumulative Production Curve*
}

\author{
By
}

\author{
Kiyomitsu FuJII $*$ \\ (Manuscript received April 27, 1954)
}

\begin{abstract}
By the use of both reservoir data and material balance equation, theoretical cumulative production curves are obtained. Applying these curves the fundamental properties of cumulative production curves are explained in this paper.
\end{abstract}

\section{Introduction}

There are many methods to estimate future production of an oil reservoir, and one of them is to use a cumulative production curve. As the production of oil from a reservoir is affected by all physical properties of the reservoir, the cumulative production curve is also affected by reservoir conditions. Therefore, the theoretical cumulative production curves are obtained by the use of both reservoir data and material balance equation.

Because a cumulative production curve is obtained directly from a production decline curve, there are common properties in these curves. Factors used as well as a method of calculating cumulative production curve, are same as those in the calculation of decline curve ${ }^{1)}$. As in the study of decline curve, the following assumptions are made in the calculation: (1) oil in its initial condition is saturated by gas, (2) free gas does not exist in the reservoir, (3) the producing formations are regular homogenous, and horizontal, (4) water drive and gravity effect are negligible, (5) the formation has continuity of physical properties, and (6) the production method is always constant, and the oil is produced at capacity.

\section{Effects of Factors upon cumulative Production Curve}

The cumulative production curves in

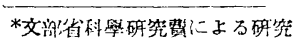

**Tokyo University this chapter are calculated upon assumptions that oil is produced from a reservoir with a single well and containing $100,000 \mathrm{kl}$ (kiloliter) of oil, and that initial production as being $100 \mathrm{kl}$ per unit time. In this paper a reservoir with above characteristics shall be referred to as "standard reservoir," and the cumulative production curve of such reservoir, "standard cumulative production curve." Reservoirs with condition other than above will be discussed in the following chapter.

Results calculated are shown in Table 1 and in Figs. 1, 2, 3 and 4. From these figures and table general properties of cumulative production curves are explained as follows :

(1) Effect of Relative Permeability:

The effect of relative permeability upon cumulative production curve is shown in Fig. 1. Calculations are based upon following assumptions: (1) the initial reservoir pressure is $100 \mathrm{~kg} / \mathrm{cm}^{2}$, (2) the gravity of oil is $30^{\circ} \mathrm{API},(3)$ the saturation of interstitial water is zero, and (4) the relative permeabilities to oil are $A$ and $B$, and the relative permeabilities to gas are $\mathrm{a}, \mathrm{b}$ and $\mathrm{c.}$ * Fig. 1 indicates that the relative permeability has considerable effect upon cumulative production curve. If free gas does not flow through a reservoir, the cumulative production increases with time. When free gas begins to flow through a reservoir, the increase of cumulative production ceases.

(2) Effect of Gravity of Oil : 
The effect of gravity of oil upon cumulative production curve is shown in Fig. 2. Calculations are based upon following assumptions: (1) the initial reservoir pressure is $100 \mathrm{~kg} / \mathrm{cm}^{2}$, (2) the relative permeability to oil is Curve $A^{*}$, (3) the saturation of interstitial water is zero, and (4) the gravity of oil is $20^{\circ} \mathrm{API}, 30^{\circ} \mathrm{API}$, respectively. Fig. 2 indicates that the gravity of oil has little effect upon cumulative production curve.

(3) Effect of Interstitial water:

The effect of interstitial water upon cumulative production curve is shown in Fig. 3. Calculations are based upon following assumptions: (1) the initial reservoir pressure is $100 \mathrm{~kg} / \mathrm{cm}^{2}$, (2) the gravity of oil is $30^{\circ} \mathrm{API},(3)$ the relative permeability to oil is Curve $A^{*}$, and (4) the saturation of interstitial water is $0 \%$, $20 \%$ and $30 \%$, respectively. Fig. 3 shows that the effect of interstitial water is great, and that as interstitial water increases the cumulative production increases.

(4) Effect of Initial Reservoir Pressure:

The effect of initial reservoir pressure upon cumulative production curve is shown in Fig. 4. Calculations are based upon following assumptions: (1) the gravity of oil is $30^{\circ} \mathrm{API},(2)$ the relative premeability to oil is Curve $A^{*}$, ( 3 ) the saturation of interstitial water is zero, and (4) the initial pressure is $100 \mathrm{~kg} / \mathrm{cm}^{2}$ 。 $60 \mathrm{~kg} / \mathrm{cm}^{2}$ and $30 \mathrm{~kg} / \mathrm{cm}^{2}$, respectively. Fig. 4 shows that the initial reservoir pressure has little

Fig. 1. Effect of relative permeability upon cumulative production curve.

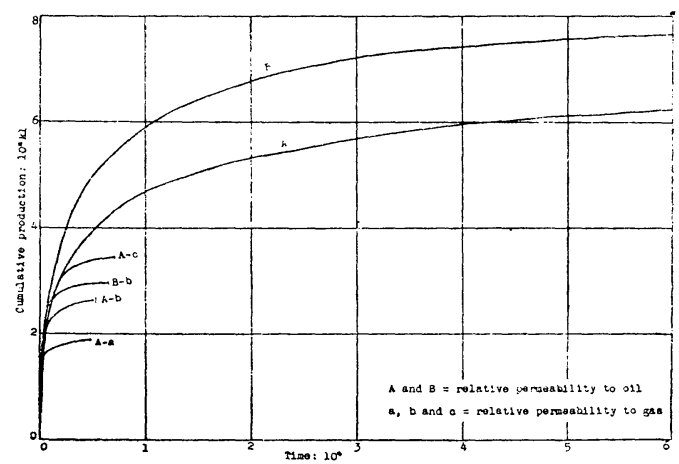

*Relative permeabilities are shown in Fig. 1 in "Fundamental Properties of Decline Curve ".1)
Fig. 2. Effect of gravity of oil upon cumulative production curve.

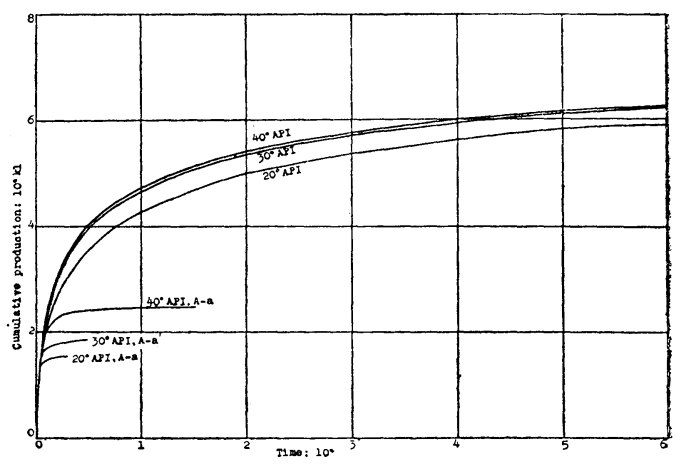

Fig. 3. Effect of interstitial water upon cumulative production curve.

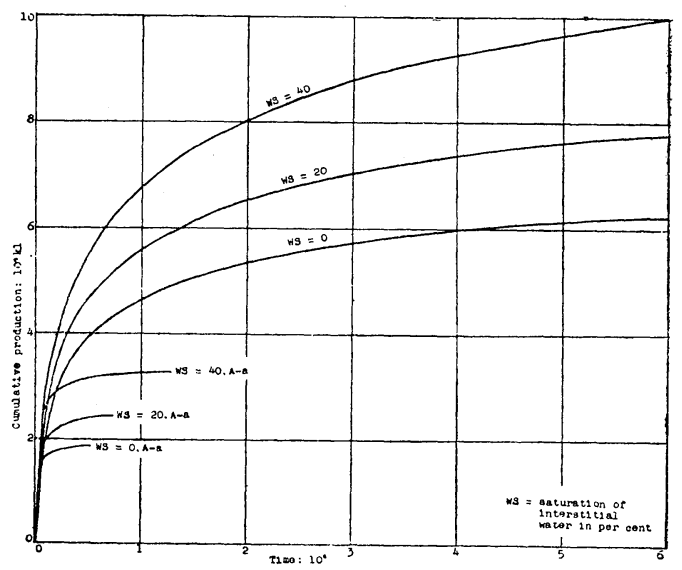

Fig. 4. Effect of initial reservoir pressure upon cumulative production curve.

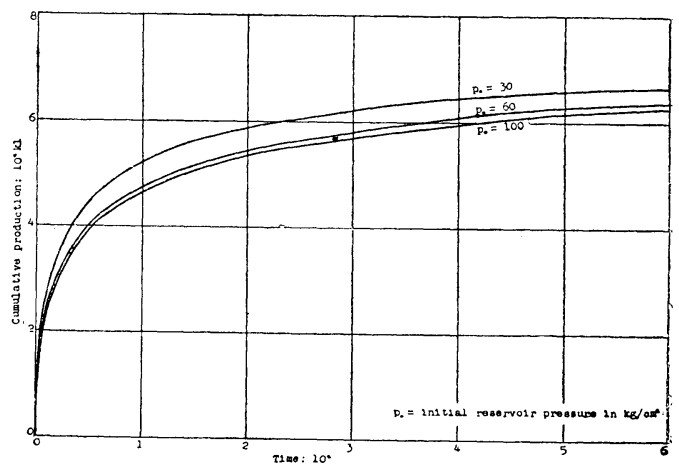

effect upon cumulative production curve.

Equations of cumulative production curves of the reservoir through which free gas does not flow are shown in Table 1 . 
Table 1. Cumulative Production Curves

\begin{tabular}{|c|c|c|c|c|c|}
\hline${ }^{\circ} \mathrm{API}$ & $\mathrm{k}_{\circ}$ & $\begin{array}{l}\text { WS } \\
\%\end{array}$ & $\underset{\mathrm{kg} / \mathrm{cm}^{2}}{\mathrm{p}_{\circ}}$ & $300<t<1000$ & $1000<\mathrm{t}$ \\
\hline 30 & $\mathrm{~A}$ & 0 & 100 & $C=\frac{34600 t}{493+t}$ & $\mathrm{C}=\frac{12200 \mathrm{t}^{1.15}}{476+\mathrm{t}}$ \\
\hline 30 & $\mathrm{~B}$ & 0 & 100 & $\mathrm{C}=\frac{42000 \mathrm{t}}{540+\mathrm{t}}$ & $\mathrm{C}=\frac{21000 \mathrm{t}^{1.12}}{735+\mathrm{t}}$ \\
\hline 30 & $\mathrm{~A}$ & 20 & 100 & $\mathrm{C}=\frac{41200 \mathrm{t}}{568+\mathrm{t}}$ & $\mathrm{C}=\frac{13600 \mathrm{t}^{1.16}}{564+\mathrm{t}}$ \\
\hline 30 & $\mathrm{~A}$ & 40 & 100 & $C=\frac{45000 t}{580+t}$ & $\mathrm{C}=\frac{12530 \mathrm{t}_{1.19}}{631+\mathrm{t}}$ \\
\hline 30 & $\mathrm{~A}$ & 0 & 60 & $\mathrm{C}=\frac{35000 \mathrm{t}}{492+\mathrm{t}}$ & $\mathrm{C}=\frac{11200 \mathrm{t}^{1.16}}{440+\mathrm{t}}$ \\
\hline 30 & A & 0 & 30 & $C=\frac{41000 t}{525+t}$ & $\mathrm{C}=\frac{18100 \mathrm{t}^{1.12}}{540+\mathrm{t}}$ \\
\hline 40 & $\mathbf{A}$ & 0 & 100 & $\mathrm{C}=\frac{35000 \mathrm{t}}{497+\mathrm{t}}$ & $\mathrm{C}=\frac{13670 \mathrm{t}^{1.14}}{526+\mathrm{t}}$ \\
\hline 20 & $\mathrm{~A}$ & 0 & 100 & $C=\frac{31100 t}{531+t}$ & $\mathrm{C}=-\frac{9400 \mathrm{t}^{1.17}}{494+\mathrm{t}}$ \\
\hline
\end{tabular}

$\mathrm{k}_{\circ}=$ relative permeability to oil, $\mathrm{WS}=$ saturaton of interstitial water in per cent, $\mathrm{p}_{\circ}=$ initial reservoir pressure in $\mathrm{kg} / \mathrm{cm}^{2}$

\section{Properties of Cumulative Production Curve of General Reservoirs}

This chapter treats of properties of cumulative production curves derived from those reservoirs with conditions different from those discussed in the foregoing chapter. A "standard curve" shown in Table 1 is expressed in the following simplified form :

$$
C=f(t)
$$

where $C$ =cumulative production of oil

$$
t=\text { time }
$$

When number of well, initial producduction, or quantity of reservoir oil varies, Eq. (1) must be altered. Since these factors affect cumulative production curves in the same manner that they affect decline curves, the equations shown in the study of decline curve $^{1)}$ are directly applied to cumulative production curve.

(1) Effect of Number of Wells :

Instead of Eq. (1), the equation of cu* Coefficient $\mathrm{K}$ is explained in the study of decline
curve.1) mulative production curve of a well producing from a reservoir with $n$ wells is written as follows:

$$
C=f(n t)
$$

(2) Effect of Initial Production:

When the initial production is $m$ times as much as that of a standard reservoir, the following equation is obtained:

$$
C=f(m t / K)
$$

(3) Combined Effects of Number of Wells and Initial Production:

The equation of cumulative production curve of a well producing from a reservoir with $n$ wells and having initial production of $(100 \mathrm{~m}) \mathrm{kl}$ is obtained by combining Eqs. (2) and (3):

$$
C=f(m n t / K)
$$

(4) Effect of quantity of Reservoir Oil:

When quantity of reservoir oil is $l$ times as much as that of a standard reservoir, the following equation is obtained:

$$
C=l f(t / l)
$$

(5) Combined Effects of Three Factors: The equation for a reservoir with $n$ 
Fig. 5. Cumulative production curves of oil reservoirs in Japan.

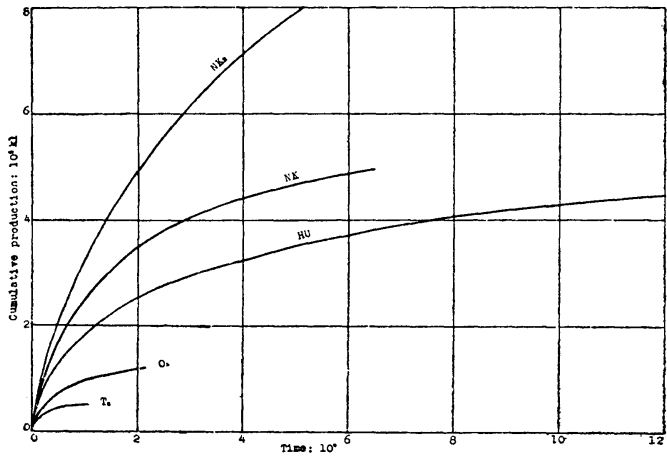

Fig. 6. Cumulative production curves of oil reservoirs in Japan.

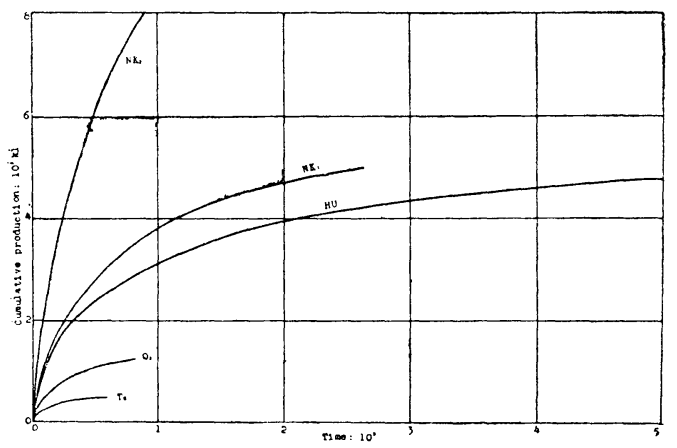

wells, of which initial production is $m$ times as much as that of a standard reservoir, and containing $l$ times as much oil as that of a standard reservoir, is obtained by combining equations mentioned above:

$$
C=l f(m n t / l K)
$$

By the application of both standard curves and equations shown above a cumulative production curve of any oil field is analysed theoretically, and inversely, a cumulative production curve of any reservoir conditions is made without difficulty.

\section{Cumulative Production Curves of Oil Fields in Japan}

Applying the method explained in the study of decline curve ${ }^{1)}$, a cumulative production curve of a reservoir with a simple condition is derived from a cumulative production curve of a reservoir with varied conditions. In comparison with theoretical cumulative production curves shown in
Figs. 1,2, 3 and 4, the cumulative production curve leads to the understanding of reservoir conditions.

Cumulative production curves of oil reservoirs* in Japan are shown in Figs. 5 and 6. In Fig. 5 cumulative production curves of reservoirs with a single well are indicated. In Fig. 6 cumulative production curves of reservoirs with a single well of which initial production is $100 \mathrm{kl}$ per unit time are indicated. These curves resemble the theoretical curves of reservoirs through which free gas does not flow.

\section{Conclusions}

(1) Because a cumulative production curve is obtained directly from a production decline curve, there are common properties in these curves.

(2) Cumulative production curves are affected by many factors. Effects of relative permeability, gravity of oil, interstitial water, and initial reservoir pressure are shown in the figures.

(3) By the application of both standard curves and equations shown in this paper, a cumulative production curve of any oil field can be analysed, and inversely, a curve of any reservoir condition can be made.

(4) Cumulative production curves of oil reservoirs in Japan are similar to theoretical curves.

\section{Reference}

1) K. Fujii: “Fundamental Properties of Decline Curve," Journal of the Japanese Association of Petroleum Technologists, Vol. 18, No. 6, Nov., 1953, and Vol. 19, No. 2, March, 1954.

\section{[要旨]}

絮計曲線の基本的性質

マテッアルバランスの式と油層の物理的性質を表わ す係数を用いるととにより, 石油の痖出量に関する理論 的な累計曲線を得る。乙れを用いて累計曲線の基本的性 質を知るととができる。この性質を利用ずるととによ り，油田の累計曲線を分析し，わるいは逆に理論的曲線 を合成するととができる。

*These reservoirs are identical to those discussed in the study of decline curve.1) 